\title{
Correction to: Predominance of Fourth Panzootic Newcastle Disease Virus Subgenotype VII.1.1 in Iran and Its Relation to the Genotypes Circulating in the Region
}

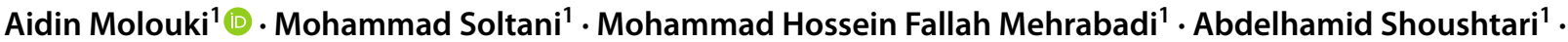 \\ Alireza Abtin ${ }^{1}$. Mohsen Mahmoudzadeh Akhijahani ${ }^{1}$. Mohammad Abdoshah ${ }^{1}$. Seyed Ali Pourbakhsh ${ }^{1}$. \\ Esmaeel Allahyari ${ }^{2} \cdot$ Arash Ghalyanchilangeroudi ${ }^{3}$. Marc Engelsma ${ }^{4} \cdot$ Swee Hua Erin Lim ${ }^{5}$
}

Published online: 14 August 2021

○) Springer Science+Business Media, LLC, part of Springer Nature 2021
Publisher's Note Springer Nature remains neutral with regard to jurisdictional claims in published maps and institutional affiliations.

The original version of this article contained a mistake in the co-author names "Mohammad Sotani and Esameel Allahyari". The correct co-author names should be Mohammad Soltani and Esmaeel Allahyari.

The original article can be found online at https://doi.org/10.1007/ s00284-021-02572-z.

Aidin Molouki

a.molouki@rvsri.ac.ir

$\triangle$ Mohammad Hossein Fallah Mehrabadi

mhf2480@yahoo.com

1 Department of Avian Diseases Research and Diagnostics, Razi Vaccine and Serum Research Institute, Agricultural Research, Education and Extension Organization (AREEO), Karaj, Iran

2 Faculty of Veterinary Medicine, Urmia University, Urmia, Iran

3 Department of Microbiology and Immunology, Faculty of Veterinary Medicine, University of Tehran, Tehran, Iran

4 Wageningen Bioveterinary Research, Wageningen University and Research, Lelystad, The Netherlands

5 Health Sciences Division, Abu Dhabi Women's College, Higher Colleges of Technology, 41012 Abu Dhabi, United Arab Emirates 